IZA DP No. 8966

Urbanization, Natural Amenities, and Subjective Well-Being: Evidence from U.S. Counties

John V. Winters

Yu Li

April 2015 


\title{
Urbanization, Natural Amenities, and Subjective Well-Being: Evidence from U.S. Counties
}

\author{
John V. Winters \\ Oklahoma State University \\ and IZA \\ Yu Li \\ Oklahoma State University
}

Discussion Paper No. 8966

April 2015

IZA

P.O. Box 7240

53072 Bonn

Germany

Phone: +49-228-3894-0

Fax: +49-228-3894-180

E-mail: iza@iza.org

Any opinions expressed here are those of the author(s) and not those of IZA. Research published in this series may include views on policy, but the institute itself takes no institutional policy positions. The IZA research network is committed to the IZA Guiding Principles of Research Integrity.

The Institute for the Study of Labor (IZA) in Bonn is a local and virtual international research center and a place of communication between science, politics and business. IZA is an independent nonprofit organization supported by Deutsche Post Foundation. The center is associated with the University of Bonn and offers a stimulating research environment through its international network, workshops and conferences, data service, project support, research visits and doctoral program. IZA engages in (i) original and internationally competitive research in all fields of labor economics, (ii) development of policy concepts, and (iii) dissemination of research results and concepts to the interested public.

IZA Discussion Papers often represent preliminary work and are circulated to encourage discussion. Citation of such a paper should account for its provisional character. A revised version may be available directly from the author. 
IZA Discussion Paper No. 8966

April 2015

\section{ABSTRACT}

\section{Urbanization, Natural Amenities, and Subjective Well-Being: Evidence from U.S. Counties ${ }^{*}$}

This paper examines the effects of county-level urbanization and natural amenities on subjective well-being (SWB) in the U.S. SWB is measured using individual-level data from the Behavioral Risk Factor Surveillance System (BRFSS) which asks respondents to rate their overall life satisfaction. Using individual-level SWB data allows us to control for several important individual characteristics. The results suggest that urbanization lowers SWB, with relatively large negative effects for residents in dense counties and large metropolitan areas. Natural amenities also affect SWB, with warmer winters having a significant positive effect on self-reported life-satisfaction. Implications for researchers and policymakers are discussed.

JEL Classification: $\quad$ 100, Q00, R00

Keywords: $\quad$ subjective well-being, urbanization, population density, amenities, quality of life

Corresponding author:

John V. Winters

Oklahoma State University

331 Business Building

Stillwater, OK 74078-4011

USA

E-mail: jvwinte@okstate.edu

The authors thank Randy Jackson, Conrad Puozaa, Dan Rickman, Heather Stephens, and participants at the 2015 Southern Regional Science Association Meetings for helpful comments. Any errors are the responsibility of the authors. 


\section{Introduction}

Happiness, life-satisfaction, and well-being are important topics for individuals, policymakers, and researchers, but there is still much that is unknown about these outcomes. Researchers interested in these topics often analyze data from surveys that ask individuals to report their subjective assessment of their own life-satisfaction, which is commonly referred to as subjective well-being (SWB). A number of factors have been shown to systematically affect SWB. Reviews of the SWB literature are provided by Diener and Biswas-Diener (2002), Dolan et al. (2008) and MacKerron (2012).

Many researchers have hypothesized that individual well-being may be considerably affected by the physical, social, and economic environment in which the individuals are situated. There is some support for this contention using data from countries around the world, but empirical research on geographic differences in subjective well-being across the U.S. has been relatively scarce largely because of limited data. However, the Behavioral Risk Factor Surveillance System (BRFSS) began asking individuals to report their subjective well-being in 2005 and provides large samples sizes and geographic identifiers needed to reliably assess spatial differences in SWB across the U.S. Oswald and Wu $(2010,2011)$ and Glaeser et al. (2014) have examined these data and documented that there are indeed differences in subjective well-being across states and metropolitan areas in the U.S., but there are still numerous issues in need of further exploration to increase our understanding of the causes and consequences of these differences.

This paper uses the 2005-2010 BRFSS to examine the effects of county urbanization and natural amenities on individual subjective well-being. Specifically, we measure county urbanization in two separate ways, first based on a single continuous variable for population 
density and then based on a set of categories for metropolitan status and size. Natural amenities examined relate to weather, topography, and proximity to bodies of water. We use individuallevel data and therefore can also control for individual characteristics that could confound analyses using aggregate data. Our approach to measuring urbanization combined with using individual level data is novel in the SWB literature. Additionally, we are the first researchers to our knowledge to examine the effects of county-level natural amenities on SWB across the U.S.

Previewing the results, we find evidence that urbanization lowers individual subjective well-being, especially for residents of dense counties and large metropolitan areas. We also find consistent evidence that areas with warmer Januaries have happier residents. These results have important implications for researchers and policymakers interested in improving well-being. Specifically, policies that increase (decrease) urbanization may decrease (increase) individual well-being. Furthermore, Lucas (2014) suggests that local subjective well-being levels predict future population growth. Planners and forecasters need to be aware of these differences in wellbeing across areas.

\section{Conceptual Framework and Literature Review}

\subsection{General Considerations}

Research on subjective well-being has considered a number of possible individual determinants including age, sex, race, ethnicity, marital status, presence of children, employment status, education, and income. Though not the focus of the current study, there is an especially large literature examining the effects of income on subjective well-being. Much of this literature following Easterlin (1974) has shown that increases in average income levels do not necessarily increase average happiness levels. Researchers have suggested that this paradoxical result may 
occur because economic growth over time raises individual aspirations, so that individuals need a higher income to achieve a given level of life-satisfaction (Easterlin 1995; Easterlin 2001; Proto and Rustichini 2015). Similarly, it may be that individuals judge their life-satisfaction based on how well they are doing relative to others.

Various locational characteristics have also been posited to affect individual well-being. For example, an individual's well-being in a given location could be affected by local labor market conditions, prices of local goods and services, and the presence and quality of locationspecific amenities and disamenities. In particular, individual utility is thought to be increasing in the local wage level and amenities and decreasing in the level of housing prices and disamenities. However, there is a pervasive belief that individuals' ability to migrate from one place to another should greatly reduce the extent of well-being differences across places (Roback 1982; Winters 2009; Oswald and Wu 2011; Glaeser et al. 2014).

Much research in regional science and urban economics posits that areas should achieve a spatial equilibrium, at least in the long run. ${ }^{1}$ The spatial equilibrium hypothesis suggests that freely mobile individuals with identical skills and preferences should receive equal utility across all areas. If not, some individuals will have an incentive to move. More specifically, individuals will move from areas offering low levels of utility to areas offering higher utility. As they relocate, they alter local markets for both labor and housing by increasing (decreasing) the supply of labor and the demand for housing in their new (old) locations. In unconstrained competitive markets, prices will adjust to achieve equilibrium. As workers move from low utility to high utility areas, wages and housing prices will adjust to push markets toward spatial

\footnotetext{
${ }^{1}$ A large strain of this literature follows Rosen (1979) and Roback (1982) to estimate implicit values of locationspecific amenities using hedonic regressions of wages and housing prices; the estimated implicit amenity values are often used to rank areas based on amenity-based quality of life. Recent examples for the U.S. include Winters (2011) and Winters (2013). A recent review is provided by Rickman (2014).
} 
equilibrium. Specifically, population growth will bid up housing prices and apply downward pressure on wages, so that the initial utility gap between the areas diminishes.

However, researchers have documented that there are indeed spatial differences in selfreported life-satisfaction, even controlling for individual differences such as age, race, ethnicity, and education (Oswald and Wu 2010, 2011; Glaeser et al. 2014). A natural next question then becomes what is causing these spatial differentials in SWB? Do they represent short-term differences from transitory shocks that require movement from one equilibrium to another? Do they simply capture unobserved differences in skills and preferences across workers in different areas? Glaser et al. (2014) suggest that spatial differentials in SWB may result because individual utility depends on more than just what one considers when providing a subjective response to typical life-satisfaction questions; specifically, individuals may prefer to take actions that help achieve various long-term goals yet make them less happy, at least at the time of the survey.

Another possible explanation for spatial SWB differentials is that there may be barriers to migration that prevent the spatial arbitrage process from fully equating happiness across areas. The U.S. has historically experienced relatively high internal migration rates compared to other developed countries, but internal migration has fallen in the U.S. in recent years perhaps because of decreased responsiveness to spatially asymmetric demand shocks (Partridge et al. 2012). Furthermore, Krupka (2009) suggests that individuals may make location-specific human capital investments that increase the benefit they receive from living near familiar amenities and deter them from moving to highly dissimilar areas. ${ }^{2}$ Krupka and Donaldson (2013) suggest that

\footnotetext{
${ }^{2}$ For example, persons who grow up near snow-covered mountains are more likely to make investments learning to ski, while persons growing up near warm coasts are more likely to make investments learning to surf. Once such location-specific investments are made, they increase the utility from residing in an area offering complementary amenities.
} 
heterogeneous moving costs combined with housing supply constraints may bias traditional hedonic estimates of amenity values. Location-specific preferences, heterogeneous moving costs, and other frictions constraining mobility imply that infra-marginal residents in one city may achieve different utility levels than infra-marginal residents in another city. Thus, spatial arbitrage in housing and labor markets may equate utility across areas for marginal migrants without doing so for infra-marginal migrants. ${ }^{3}$

While life-satisfaction responses may not equal utility, an individual's life-satisfaction at a point in time certainly has an important effect on utility and is an important outcome for researchers to study. The current paper examines the effects of local urbanization and natural amenities on individuals' self-reported life satisfaction. That these factors might affect wellbeing is not new, but the approach taken in this paper is novel in many ways and aims to provide additional insights to the existing literature.

Urbanization might affect individual well-being in numerous ways, both positively and negatively (Easterlin et al. 2011). Positive effects of urbanization on well-being might result from agglomeration economies and increased variety and quality of consumption opportunities. Agglomeration economies due to thick labor markets, intermediate input sharing, and knowledge spillovers are thought to increase worker productivity and wages in larger and denser areas (Puga 2010), which could increase life-satisfaction, ceteris paribus. Big cities may also offer better and more diverse consumption opportunities for numerous goods such as museums, theaters, music, professional sports, public transit, heath care, and specialized restaurants (Glaeser et al. 2001; Albouy 2008; Berry and Waldfogel 2010). However, urbanization also likely increases living costs, congestion, pollution, traffic, and crime, all of which can make life more unpleasant

\footnotetext{
${ }^{3}$ This possibility also lends support for the potential efficacy of place-based policies (Partridge and Rickman 2007 , 2008; Partridge et al. 2015).
} 
and decrease life-satisfaction (Smyth et al. 2008; Berry and Okulicz-Kozaryn 2011; Sander 2011; Navarro-Azorín, and Artal-Tur 2015). The net effect of urbanization on well-being is ambiguous and depends on individual preferences for the good and bad attributes that cities possess. The current paper does not try to empirically sort out the magnitudes of the various mechanisms by which urbanization might affect life-satisfaction. Instead, we focus on the overall effect.

A natural amenity can be broadly thought of as any naturally-occurring locational attribute that makes a location more desirable. Areas with better natural amenities might be expected to increase individual well-being. More generally, researchers have suggested that amenities related to nicer weather have played a central role in regional population redistribution in the U.S., especially from the nation's "Rustbelt", i.e., the older industrial Great Lakes region, to the nation's "Sunbelt", i.e., warmer areas in the South and West regions (Rappaport 2007; Partridge 2010; Rickman and Rickman 2011; Rickman and Wang 2015). ${ }^{4}$ However, some natural amenities may be congestible, meaning that their value decreases as more people consume them; if so, this could diminish their potentially positive effect on well-being.

\subsection{Literature on Spatial SWB Differentials}

Oswald and $\mathrm{Wu}(2010,2011)$ use the BRFSS to show that there are significant differences in SWB across states in the U.S. even after controlling for a large number of individual characteristics. Oswald and Wu (2010) also show that these SWB differences are correlated with state quality-of-life rankings based on hedonic pricing of locational amenities. Specifically, Oswald and $\mathrm{Wu}$ (2010) find that states with better quality of life have higher

\footnotetext{
${ }^{4}$ Faggian et al. (2012) suggest that natural amenities may play a less important role for well-being in Europe than in the USA, but Rodríguez-Pose and Ketterer 2012) find that natural amenities are still quite important determinants of well-being in Europe.
} 
subjective well-being, but they do not examine the relationships with specific amenities. The Oswald and Wu $(2010,2011)$ state SWB differences appear to be at least somewhat related to climatic differences between the Sunbelt and Rustbelt regions, but they do not provide formal evidence on this.

Natural amenities have also been considered to affect life-satisfaction and well-being by other researchers for other areas. Climate variables, in particular, have received considerable attention in the subjective well-being literature (Rehdanz and Maddison 2005; Brereton et al. 2008; Moro et al. 2008; Fischer et al. 2011; Maddison and Rehdanz 2011; Cuñado and Pérez de Gracia 2013). The literature suggests that both very hot summers and very cold winters reduce life-satisfaction. ${ }^{5}$

Glaeser et al. (2014) show that there are meaningful differences in subjective well-being across metropolitan areas of the U.S. They show that persons in declining urban areas experience lower SWB, and this appears particularly true for those in the nation's Rustbelt. Glaeser et al. (2014) also report regression-adjusted mean SWB levels for selected metropolitan areas showing that the nation's largest metropolitan area, the New York City MSA, had the lowest life-satisfaction level in the country. Other large MSAs like Los Angeles, Chicago, Boston, San Francisco, and San Jose tended to perform poorly as well, though there were some exceptions including Washington D.C. Glaeser et al. (2014) do not systematically examine the effects of population density or metropolitan area size on SWB.

The literature on spatial differences in subjective well-being across the U.S. is relatively small, and we make several contributions relative to the previous literature. Our approach to measuring urbanization at the county-level combined with controlling for individual

\footnotetext{
${ }^{5}$ For a given place and season, transitory weather conditions may also affect reported life-satisfaction (Connolly 2013).
} 
characteristics is novel in the literature. A few studies have examined the effects of population density on subjective well-being (Cramer et al. 2004; Moro et al. 2008; Berry and OkuliczKozaryn 2011; Florida et al. 2013), but the only other study to do so using U.S. county-level data (Lawless and Lucas 2010) uses county averages to examine correlations and does not control for individual characteristics. We are also the first researchers to our knowledge to explicitly examine the effects of metropolitan status and size and county-level natural amenities on subjective well-being in the U.S.

\section{Empirical Approach}

This paper combines individual-level data from the 2005-2010 BRFSS with county-level data on urbanization and natural amenities. The dependent variable is a measure of subjective well-being from the BRFSS. During this time period, the BRFSS asked individuals "In general, how satisfied are you with your life?" Respondents were to choose answers from the following categories: Very satisfied, Satisfied, Dissatisfied, or Very dissatisfied. Our analysis codes the life satisfaction categories from one to four with one being Very dissatisfied and four being Very satisfied, so that our variable is increasing with life satisfaction. A few survey participants either refused or were unsure about how to respond to the life satisfaction question; persons with invalid responses are excluded from the analysis. The analytical sample is also restricted to persons ages 18-85 living in a county that is identifiable in the BRFSS excluding Alaska and Hawaii. The BRFSS identifies a total of 2361 counties across this period but does not identify small counties with very few observations because of confidentiality concerns. Some of the natural amenity data discussed below are unavailable for Alaska and Hawaii, necessitating their exclusion. 
We use ordinary least squares (OLS) regression ${ }^{6}$ to estimate variants of the following equation:

$$
\text { LifeSat }_{i j}=X_{i j} \beta+Z_{j} \theta+\varepsilon_{i j}
$$

The dependent variable, LifeSat ${ }_{i j}$, is life satisfaction for person $i$ in county $j, X_{i j}$ includes several individual characteristic variables and $Z_{j}$ includes county-level variables such as natural amenity and urbanization measures. Individual characteristics are included to control for observable differences in individuals across areas. These include dummy variables for sex, race/ethnicity, five-year age group, marital status, employment status, highest education completed, number of adults in the household, and a continuous variable for the ratio of minor children to adults in the household. ${ }^{7}$ The regressions also include dummies for survey year and month. A full list and summary statistics for individual and county-level variables included in the analysis are reported in Table 1.

The interest in this study is on the effects of urbanization and natural amenities on subjective well-being. We measure urbanization in two separate ways. We first measure urbanization using a continuous variable based on the population density in the county in year 2000, where density is computed as the county population (in thousands) divided by the county land area in square miles. Our second approach for measuring the extent of urbanization is based on metropolitan area status and size. Specifically, we use year 2000 county population data and 2003 metropolitan and micropolitan area component classifications (both from the U.S. Census

\footnotetext{
${ }^{6}$ Results are qualitatively robust to using ordered probit, but OLS permits easier interpretation and is used by Oswald and $\mathrm{Wu}(2010,2011)$ as well.

${ }^{7}$ We do not include controls for income in our main results, because incomes partially depend on the extent of urbanization. Furthermore, spatial equilibrium theory suggests that local income and wages are jointly determined with the local cost of living and amenities. Since we cannot reliably include a full set of amenities, we choose to focus on the overall effects of urbanization and natural amenities on life-satisfaction.
} 
Bureau) to assign each county to one of six categories. We classify metropolitan statistical areas (MSAs) as either small, medium, large, or very large based on MSA population groupings of 0-249,999, 250,000-999,999, 1,000,000-3,999,999 and 4,000,000 or more, respectively. ${ }^{8} \mathrm{We}$ also divide non-metropolitan areas into micropolitan areas and non-urban areas. Non-urban areas are defined as areas that are part of neither a metropolitan nor micropolitan area. In the regression results below, non-urban counties are the excluded base group; coefficients for the metro status and size dummy variables are measured relative to this base group.

We examine the effects of nine county-level natural amenity measures; the first six were obtained from the United States Department of Agriculture (USDA) Economic Research Service (ERS) natural amenity database and the other three were hand-coded based on consulting maps. The six USDA variables are described in McGranahan (1999) and include mean January temperature, mean January sunlight hours, mean July temperature, mean July relative humidity, topography (measured on a scale of 1-21 with higher values indicating a more mountainous land surface), and the percentage of total county area covered by water. The other three natural amenity measures are dummy variables for being located on the Pacific Ocean, Atlantic Ocean, and Gulf of Mexico. Having a warmer and sunnier January is expected to increase lifesatisfaction, while having a hotter and more humid July is expected to reduce life-satisfaction. The effect of topography is somewhat ambiguous; more mountainous topography may provide greater consumption amenities but make production more difficult and reduce employment outcomes. Water coverage and proximity to a coast are expected to provide greater recreational opportunities and increase life-satisfaction.

\footnotetext{
${ }^{8}$ The small and medium MSA size classifications were defined to be consistent with definitions used by the United States Department of Agriculture Economic Research Service. The 4,000,000 population boundary between large and very large MSAs was chosen in part so that there are a reasonable number of MSAs and individual observations in both groups. The results below are qualitatively robust to moderately different boundary definitions.
} 
The later years of our data correspond to the Great Recession of 2007-2009 and the ensuing slow recovery. Year dummies will capture aggregate differences over time, but the economic downturn was more severe in some areas than others. Therefore, we also examine the robustness of our results to including the county annual unemployment rate computed by the U.S. Bureau of Labor Statistics (BLS) in its Local Area Unemployment System (LAUS). Living in a stronger local labor market with lower unemployment rates is expected to increase wellbeing. Empirical evidence routinely finds that being unemployed reduces individual subjective well-being (e.g. Clark and Oswald 1994; Winkelmann and Winkelmann 1998; Pittau et al. 2010; Oswald and $\mathrm{Wu} 2011$ ), but there is also evidence that the local unemployment rate in an area reduces the well-being of its residents, even among those who are currently employed (Helliwell and Huang 2014). This latter effect could be because of increased risk of becoming unemployed or increased perception of unemployment risk.

\section{Empirical Results}

We estimate the SWB equation for several regression specifications that include different sets of control variables in order to examine the sensitivity of the results. All regressions include month and year dummies and cluster standard errors by county.

\subsection{Results for Urbanization Measures}

Table 2 presents the results for the effects of urbanization on subjective well-being. We report results for the two measurement approaches in panels A and B. Results for the population density variable are reported in panel A, and results for the metropolitan area status and size dummies are reported in panel B. Each panel includes regression results for four specifications 
with differing variables included. Columns 1-3 include only one of the two approaches to measuring urbanization, and column 4 includes both the population density and the metro status and size dummies jointly. Column 1 includes the urbanization measure(s) but excludes all other variables except for month and year dummies. Column 2 adds the individual controls. Column 3 adds the county unemployment rate and the natural amenity variables as controls (results for natural amenities are reported separately in Table 3). Column 4 includes both sets of urbanization measures along with all other variables in previous columns.

The results in Panel A suggest that urbanization as measured by county population density has a negative effect on an individual's subjective well-being. The coefficient is negative and statistically significant in all four columns. Interestingly, the coefficient does fall when individual controls are included, e.g. the coefficient falls from -0.0037 in column 1 to -0.0022 in column 2. This suggests that studies using aggregate data that do not control for individual characteristics may produce inaccurate results because of differences in individuals across areas. The specification in column 3 that also includes amenities and the unemployment rate yields a coefficient for population density of -0.0021 . Adding the metro status and size dummies lowers the population density coefficient to -0.0017 , but these are both measures of urbanization, so column 4 partials out some of the urbanization effect.

Panel B examines the effects of the metro status and size dummies; the omitted base group is non-urban counties. With no controls in column 1, it appears that the relationship between urban utility and urban size has an inverted U-shape. Specifically, the highest wellbeing occurs in micropolitan areas (0.0158), small metro areas (0.0236), and medium metro areas (0.0159); large and very large metros are not statistically different from non-urban areas. However, controlling for individual characteristics in column 2 generates coefficients that are 
largely decreasing in urban size. Micropolitan areas and small metropolitan areas have small negative coefficients that make them statistically indistinguishable from non-urban areas. The coefficients are significantly negative for medium metros (-0.0080), large metros $(-0.0146)$, and very large metros (-0.0210). Controlling for the county unemployment rate and natural amenities increases the magnitude of the metro status and size coefficients, and the micropolitan dummy is now significant with a coefficient of -0.0047 ; the coefficients for medium, large, and very large metros are $-0.0140,-0.0220$, and -0.0257 , respectively. Adding the county population density in column 4 has no effect on the micropolitan and small metro areas coefficients, but slightly reduces the coefficients for medium (-0.0135), large (-0.0206), and very large metro areas $(-0.0186)$. Of course, the results in column 4 should be interpreted with care since we are including two competing measures of urbanization.

Collectively, the results in Table 2 suggest that both population density and metropolitan area size reduce individual life-satisfaction. There is considerable disagreement as to how cities affect the well-being of those living in them (Albouy 2008; Sander 2011; Glaeser et al. 2014). Cities certainly possess a number of both positive and negative attributes, but the empirical results in Table 2 suggest that living in dense and heavily-populated areas has an overall negative effect on an individual's subjective assessment of their own well-being. ${ }^{9}$ We do not explore the specific attributes of cities that are driving this overall negative effect, but this is an issue worthy of future exploration. Furthermore, we suggest that policymakers with the ability to influence population density and city size should be aware of our results when considering various policies.

\footnotetext{
${ }^{9}$ Recall that these results do not control for income because higher incomes are one of the main benefits of urbanization. We consider the effects of controlling for income in sensitivity analysis below.
} 


\subsection{Results for Natural Amenities}

The effects of natural amenities on life-satisfaction are reported in Table 3. Column 1 includes the nine natural amenity variables but excludes all other variables except for month and year dummies. Column 2 adds the individual controls. Column 3 adds the county unemployment rate and all of the urbanization measures as controls.

The coefficient estimates for the natural amenity variables do vary somewhat across specifications, but there are some commonalities as well. The coefficients for January temperature and January sunlight conform to expectations for all specifications, that is, they are positive and statistically significant, suggesting that warmer and sunnier Januaries increase lifesatisfaction. This is consistent with previous literature showing that people have been moving to areas with nicer weather (Rappaport 2007; Partridge 2010; Rickman and Rickman 2011; Rickman and Wang 2015). Interestingly, the coefficient estimates for January temperature in columns 2 and 3 (0.0011 and 0.0013) are twice as large as in column 1 (0.0005) with no controls. However, the coefficient for January sun decreases moving from column $1(0.0002)$ to columns 2 and 3 (0.0001 for both).

The coefficient for July temperature is statistically significantly negative in columns 1 and 3 as expected, but it is not statistically significant in column 2. The lack of robustness prevents one from drawing very strong conclusions about the effects of July heat on lifesatisfaction, but the results provide suggestive evidence that hot summers reduce lifesatisfaction. July relative humidity is significantly negative in column $1(-0.0005)$, but the effect decreases in magnitude and becomes statistically insignificant in columns 2 and 3. Topography has a negative coefficient in all specifications but is never statistically significant, preventing us 
from making strong conclusions. The percent of water area is also statistically insignificant in all specifications.

The Pacific coast dummy coefficient is negative in all specifications and is statistically significant in columns $2(-0.0234)$ and $3(-0.0237)$. The prior expectation was that proximity to the coast would increase recreational opportunities and make life more enjoyable. ${ }^{10}$ The negative effect of being on the Pacific coast may be due to high levels of congestion that more than offset the natural amenity value of the ocean and beaches. If one could enjoy these public goods peacefully, they might make life more enjoyable, but when these public goods attract lots of people, the surrounding area becomes overly congested and less pleasant. This result is unaffected by controlling for urbanization measures, but these are based on residential population. Beaches attract tourists and visitors from other counties, so that coastal counties will be more congested than indicated by the urbanization measures in this study. The Atlantic coast dummy coefficient is statistically insignificant in all specifications with columns 2 and 3 estimates being slightly negative. The Gulf coast dummy coefficient is statistically significant in column $1(0.0179)$ but insignificant in columns 2 and 3, and the estimate is slightly negative in column 3.

\subsection{Further Sensitivity Analysis}

We next further consider how sensitive the results are to additional specifications and samples. Table 4 presents some additional results for both urbanization measures and natural amenities. Column 1 reproduces results for the "base specification" with all of the variables

\footnotetext{
${ }^{10}$ It is also important to recall that we are controlling for climate variables, so that the coast dummies are capturing features unrelated to climate.
} 
included thus far, including both sets of urbanization measures simultaneously; this corresponds to column 4 of Table 2 and column 3 of Table 3.

Column 2 of Table 4 examines the effects of controlling for individual income using interval-coded survey responses in the BRFSS. It is certainly possible that higher ability (and hence higher income) individuals may differentially sort into areas based on the extent of urbanization and natural amenities. However, we also recognize that higher incomes are one of the main benefits of urbanization, and controlling for income hinders our ability to interpret the coefficients on our urbanization measures as reporting overall effects. Examining the results in column 2 , we see that the population density coefficient is still significant and slightly more negative than in column 1 (-0.0018 vs. -0.0017), but the difference is small. However, the metropolitan status and size dummy coefficients are significantly affected. The coefficients become more negative, and are strongly increasing in magnitude with metropolitan area population. For example, very large metro areas have a very large coefficient of -0.0604 .

The January temperature coefficient is slightly reduced (from 0.0013 to 0.0011 ) by controlling for income but it is still statistically significant. However, the coefficient for January sunlight is reduced and becomes statistically insignificant. Similarly, the coefficient for July temperature decreases in magnitude and is no longer significant. The lack of robustness for these two variables hinders our ability to make strong inferences about their effects on subjective wellbeing. The Pacific coast coefficient is reduced in magnitude (from -0.0237 to -0.0158) but still negative and significant. The other natural amenities remain statistically insignificant.

The results are somewhat sensitive to controlling for income, but controlling for one of the main benefits of urbanization may be inappropriate if we are not also controlling for the costs of urbanization like higher cost of living, increased congestion, etc. Controlling for cost of living 
at the county level is complicated by lack of data on non-housing prices and differences in user costs between home-owners and renters (Winters 2009, 2013), so we make no attempt to do so but this could be an area for future research. There are many possible urban amenities and disamenities and including all possible relevant characteristics is not feasible. Thus, our preferred approach in this paper is to focus on the overall effects of urbanization and natural amenities on subjective well-being. As such, our preferred results do not control for income since doing so would partial out a major benefit of large dense cities. However, it is worth emphasizing that controlling for income does not change the directional effect of urbanization on subjective well-being; it only intensifies the magnitudes of the negative effects we observe.

Column 3 of Table 4 examines of the effects of limiting the sample to years 2005-2006. The primary motivation for doing so is to recognize that the housing crash, economic recession, and generally sluggish economy experienced during years 2007-2010 affected some areas more than others. Restricting to years 2005-2006 reduces the magnitude of the density coefficient to -0.0011 , but it is still significant. The metro status and size coefficients are largely unchanged except that the coefficient for very large metropolitan areas increases in magnitude from -0.0186 to -0.0221 . The January temperature coefficient of 0.0011 is again significant and the coefficient for January sun is unchanged from the base specification. The coefficient for July temperature is now -0.0004 and not statistically significant. The coefficient for the Pacific coast dummy is now -0.0165 and not significant. Of course, using less data reduces the precision of the estimates, so we should be careful not to interpret the results for these last two variables as strong evidence of no effect.

Column 4 of Table 4 further examines the negative coefficient for the Pacific coast dummy by decomposing it into separate dummies for counties on the Pacific coast in 
Washington, Oregon, Northern California, and Southern California. Doing so has very little effect on the urbanization and other amenity coefficients relative to column 1. Interestingly though, including separate Pacific coast dummies reveals that the strong negative effect is actually a California coast effect, and the effect is large for both Northern and Southern California coastal counties with coefficients of -0.0454 and -0.0382 , respectively. This is largely consistent with findings in Oswald and Wu (2011) that California is a relatively low subjective well-being state. In further results not shown, we also find that the large negative effects for California coastal counties are robust to limiting the sample to years 2005-2006 and to controlling for individual income. We are unable to further explain this result, but we again suggest that it may be at least somewhat attributable to high levels of congestion from nonresidents that reduce the well-being of these counties' residents.

\section{Conclusion}

Most individuals care about both their own well-being and the well-being of others. Researchers and policymakers are interested in how various factors affect individual well-being, in part because they are interested in improving the well-being of others. However, there is still limited knowledge about what factors actually improve individual well-being. Locational factors have been hypothesized to affect well-being, but the previous literature offering empirical evidence is quite limited, especially for the U.S. This paper examines the effects of county-level measures of urbanization and natural amenities on subjective well-being using individual-level data from the BRFSS.

Living in an urban area conveys a number of both costs and benefits. However, the results in this study suggest that large and densely populated urban areas have negative net 
effects on individual life-satisfaction; that is, living in cities on average makes people in the U.S. less happy. Policymakers should be aware of these results. Policies that reduce the size and density of metropolitan areas may be able to improve well-being, for example, by reducing congestion, pollution, and time spent commuting.

We also find evidence consistent with expectations that more extreme climate conditions reduce subjective well-being. Specifically, warmer winter months consistently increase life satisfaction, and there is some evidence that hotter summer months reduce life satisfaction. Mobile individuals are expected to seek out areas offering them the highest well-being, so these spatial differences in SWB by climate suggest that the long-term population redistribution to areas with nicer weather is likely to continue for the foreseeable future. 


\section{References}

Albouy, David. (2008). "Are big cities bad places to live? Estimating quality of life across metropolitan areas." National Bureau of Economic Research Working Paper No. 14472.

Berry, Brian J.L., and Adam Okulicz-Kozaryn. (2011). "An urban-rural happiness gradient." Urban Geography 32.6: 871-883.

Berry, Steven, and Joel Waldfogel. (2010). "Product quality and market size.” Journal of Industrial Economics 58.1: 1-31.

Brereton, Finbarr, J. Peter Clinch, and Susana Ferreira. (2008). "Happiness, geography and the environment." Ecological Economics 65.2: 386-396.

Clark, Andrew E., and Andrew J. Oswald. (1994). "Unhappiness and unemployment.” The Economic Journal: 648-659.

Connolly, Marie. (2013). "Some like it mild and not too wet: The influence of weather on subjective well-being." Journal of Happiness Studies 14.2: 457-473.

Cramer, Victoria, Svenn Torgersen, and Einar Kringlen. (2004). "Quality of life in a city: The effect of population density." Social Indicators Research 69.1: 103-116.

Cuñado, Juncal, and Fernando Pérez de Gracia. (2013). "Environment and happiness: New evidence for Spain." Social Indicators Research 112.3: 549-567.

Dolan, Paul, Tessa Peasgood, and Mathew White. (2008). "Do we really know what makes us happy? A review of the economic literature on the factors associated with subjective well-being." Journal of Economic Psychology 29.1: 94-122.

Easterlin, Richard A. (1974). "Does economic growth improve the human lot? Some empirical evidence." In P. A. David and M. W. Reder (Eds.), Nations and Households in Economic Growth: Essays in Honor of Moses Abramowitz. Academic Press, Orlando, FL, pp. 89125.

Easterlin, Richard A. (1995). "Will raising the incomes of all increase the happiness of all?" Journal of Economic Behavior \& Organization 27.1: 35-47.

Easterlin, Richard A. (2001). "Income and happiness: Towards a unified theory." Economic Journal 111.473: 465-484.

Easterlin, Richard A., Laura Angelescu, and Jacqueline S. Zweig. (2011). "The impact of modern economic growth on urban-Rural differences in subjective well-being." World Development 39.12: 2187-2198. 
Faggian, Alessandra, M. Rose Olfert, and Mark D. Partridge. (2012). "Inferring regional wellbeing from individual revealed preferences: The 'voting with your feet' approach." Cambridge Journal of Regions, Economy and Society 5.1: 163-180.

Fischer, Ronald, and Evert Van de Vliert. (2011). "Does climate undermine subjective wellbeing? A 58-nation study." Personality and Social Psychology Bulletin 37.8: 1031-1041.

Florida, Richard, Charlotta Mellander, and Peter J. Rentfrow. (2013). "The happiness of cities." Regional Studies 47.4: 613-627.

Glaeser, Edward L., Joshua D. Gottlieb, and Oren Ziv. (2014). "Unhappy cities.” National Bureau of Economic Research Working Paper No. 20291.

Glaeser, Edward L., Jed Kolko, and Albert Saiz. (2001). “Consumer city.” Journal of Economic Geography 1.1: 27-50.

Helliwell, John F., and Haifang Huang. (2014). "New measures of the costs of unemployment: Evidence from the subjective well-being of 3.3 million Americans." Economic Inquiry 52.4: $1485-1502$.

Krupka, Douglas J. (2009). "Location-specific human capital, location choice and amenity demand." Journal of Regional Science 49.5: 833-854.

Krupka, Douglas J., and Kwame N. Donaldson. (2013). "Wages, rents, and heterogeneous moving costs.” Economic Inquiry 51.1: 844-864.

Lawless, Nicole M., and Richard E. Lucas. (2011). "Predictors of regional well-being: A county level analysis." Social Indicators Research 101.3: 341-357.

Lucas, Richard E. (2014). Life satisfaction of US counties predicts population growth.” Social Psychological and Personality Science 5.4: 383-389.

MacKerron, George. (2012). "Happiness economics from 35000 feet." Journal of Economic Surveys 26.4: 705-735.

Maddison, David, and Katrin Rehdanz. (2011). "The impact of climate on life satisfaction." Ecological Economics 70.12: 2437-2445.

McGranahan, David A. (1999). Natural amenities drive rural population change. Agricultural Economic Report No. (AER-781). United States Department of Agriculture, Economic Research Service.

Moro, Mirko, Finbarr Brereton, Susana Ferreira, and J. Peter Clinch. (2008). "Ranking quality of life using subjective well-being data." Ecological Economics 65.3: 448-460. 
Navarro-Azorín, José Miguel, and Andrés Artal-Tur. (2015). "Foot voting in Spain: What do internal migrations say about quality of life in the Spanish municipalities?" Social Indicators Research Forthcoming: DOI 10.1007/s11205-014-0804-6.

Oswald, Andrew J., and Stephen Wu. (2010). "Objective confirmation of subjective measures of human well-being: Evidence from the USA.” Science 327.5965: 576-579.

Oswald, Andrew J., and Stephen Wu. (2011). "Well-being across America." Review of Economics and Statistics 93.4: 1118-1134.

Partridge, Mark D. (2010). “The duelling models: NEG vs amenity migration in explaining US engines of growth.” Papers in Regional Science 89.3: 513-536.

Partridge, Mark D., and Dan S. Rickman. (2007). "Persistent pockets of extreme American poverty and job growth: Is there a place-based policy role?" Journal of Agricultural and Resource Economics: 201-224.

Partridge, Mark D., and Dan S. Rickman. (2008). "Place-based policy and rural poverty: Insights from the urban spatial mismatch literature." Cambridge Journal of Regions, Economy and Society 1.1: 131-156.

Partridge, Mark D., Dan S. Rickman, M. Rose Olfert, and Kamar Ali. (2012). "Dwindling US internal migration: Evidence of spatial equilibrium or structural shifts in local labor markets?” Regional Science and Urban Economics 42.1: 375-388.

Partridge, Mark D., Dan S. Rickman, M. Rose Olfert, and Ying Tan. (2015). "When spatial equilibrium fails: Is place-based policy second best?” Regional Studies:

DOI:10.1080/00343404.2013.837999.

Proto, Eugenio, and Aldo Rustichini. (2015). "Life satisfaction, income and personality." IZA Discussion Paper No. 8837.

Puga, Diego. (2010). “The magnitude and causes of agglomeration economies.” Journal of Regional Science 50.1: 203-219.

Rappaport, Jordan. (2007). "Moving to nice weather." Regional Science and Urban Economics 37.3: $375-398$.

Rehdanz, Katrin, and David Maddison. (2005). "Climate and happiness." Ecological Economics 52.1: 111-125.

Rickman, Dan S. (2014). "Assessing regional quality of life: A call for action in regional science.” Review of Regional Studies 44.1: 1-12. 
Rickman, Dan S., and Shane D. Rickman. (2011). "Population growth in high-amenity nonmetropolitan areas: What's the prognosis?” Journal of Regional Science 51.5: 863879.

Rickman, Dan S., and Hongbo Wang. (2015). “US regional population growth 2000-2010: Natural amenities or urban agglomeration?" MPRA Working Paper.

Roback, Jennifer. (1982). "Wages, rents, and the quality of life.” Journal of Political Economy: 1257-1278.

Rodríguez-Pose, Andrés, and Tobias D. Ketterer. (2012). "Do local amenities affect the appeal of regions in Europe for migrants?” Journal of Regional Science 52.4: 535-561.

Rosen, Sherwin. (1979). "Wage-based indexes of urban quality of life.” In Peter M. Mieskowski and Mahlon R. Straszheim (Eds.), Current Issues in Urban Economics. Johns Hopkins University Press, Baltimore, pp. 74-104.

Sander, William. (2011). "Location and happiness in the United States." Economics Letters 112.3: 277-279.

Smyth, Russell, Vinod Mishra, and Xiaolei Qian. (2008). "The environment and well-being in urban China.” Ecological Economics 68.1: 547-555.

Winkelmann, Liliana, and Rainer Winkelmann. (1998). "Why are the unemployed so unhappy? Evidence from panel data." Economica 65.257: 1-15.

Winters, John V. (2009). "Wages and prices: Are workers fully compensated for cost of living differences?" Regional Science and Urban Economics 39.5: 632-643.

Winters, John V. (2011). "Human capital, higher education institutions, and quality of life." Regional Science and Urban Economics 41.5: 446-454.

Winters, John V. (2013). "Differences in quality of life estimates using rents and home values." Annals of Regional Science 51.2: 377-409. 
Table 1: Summary Statistics

\begin{tabular}{|c|c|c|c|c|}
\hline Variable & Mean & Std. Dev. & Min & Max \\
\hline Life satisfaction & 3.387 & 0.631 & 1 & 4 \\
\hline Population density (in thousands per square mile) & 1.052 & 3.700 & 0.0004 & 66.951 \\
\hline Micropolitan (In a micropolitan area) & 0.176 & 0.381 & 0 & 1 \\
\hline Small metro (In metro area w/ population less than 250,000 ) & 0.151 & 0.358 & 0 & 1 \\
\hline Medium metro (In metro area w/ population $250,000-999,999$ ) & 0.221 & 0.415 & 0 & 1 \\
\hline Large metro (In metro area w/ population $1,000,000-3,999,999)$ & 0.202 & 0.401 & 0 & 1 \\
\hline Very large metro (In metro area w/ population $4,000,000$ or more) & 0.147 & 0.354 & 0 & 1 \\
\hline January mean temperature & 33.600 & 11.547 & 1.4 & 67.2 \\
\hline January mean sunlight & 149.226 & 41.212 & 48 & 266 \\
\hline July mean temperature & 74.781 & 5.569 & 55.6 & 93.7 \\
\hline July mean relative humidity & 56.783 & 15.995 & 14 & 80 \\
\hline Topography & 9.543 & 7.002 & 1 & 21 \\
\hline Percent water area & 8.198 & 13.687 & 0 & 75 \\
\hline Pacific Coast & 0.022 & 0.148 & 0 & 1 \\
\hline Atlantic Coast & 0.099 & 0.299 & 0 & 1 \\
\hline Gulf Coast & 0.030 & 0.171 & 0 & 1 \\
\hline County unemployment rate & 6.493 & 2.833 & 1.7 & 29 \\
\hline Black & 0.083 & 0.276 & 0 & 1 \\
\hline Asian & 0.012 & 0.108 & 0 & 1 \\
\hline Hispanic & 0.062 & 0.241 & 0 & 1 \\
\hline Native American & 0.013 & 0.113 & 0 & 1 \\
\hline Other non-white & 0.015 & 0.120 & 0 & 1 \\
\hline Female & 0.621 & 0.485 & 0 & 1 \\
\hline Ages 23-27 & 0.035 & 0.185 & 0 & 1 \\
\hline Ages $28-32$ & 0.054 & 0.226 & 0 & 1 \\
\hline Ages 33-37 & 0.069 & 0.253 & 0 & 1 \\
\hline Ages $38-42$ & 0.081 & 0.272 & 0 & 1 \\
\hline Ages 43-47 & 0.093 & 0.290 & 0 & 1 \\
\hline Ages $48-52$ & 0.107 & 0.309 & 0 & 1 \\
\hline Ages 53-57 & 0.111 & 0.314 & 0 & 1 \\
\hline Ages $58-62$ & 0.110 & 0.313 & 0 & 1 \\
\hline Ages 63-67 & 0.096 & 0.294 & 0 & 1 \\
\hline Ages $68-72$ & 0.079 & 0.270 & 0 & 1 \\
\hline Ages $73-87$ & 0.066 & 0.249 & 0 & 1 \\
\hline Ages $78-82$ & 0.053 & 0.224 & 0 & 1 \\
\hline Ages 83-85 & 0.022 & 0.146 & 0 & 1 \\
\hline Highest education: some high school & 0.061 & 0.240 & 0 & 1 \\
\hline Highest education: high school diploma & 0.293 & 0.455 & 0 & 1 \\
\hline Highest education: some college & 0.266 & 0.442 & 0 & 1 \\
\hline Highest education: bachelor's or higher & 0.349 & 0.477 & 0 & 1 \\
\hline Married & 0.567 & 0.495 & 0 & 1 \\
\hline Divorced & 0.143 & 0.350 & 0 & 1 \\
\hline Widowed & 0.120 & 0.325 & 0 & 1 \\
\hline Separated & 0.022 & 0.146 & 0 & 1 \\
\hline Partner & 0.024 & 0.152 & 0 & 1 \\
\hline Self-employed & 0.085 & 0.278 & 0 & 1 \\
\hline Unemployed & 0.048 & 0.213 & 0 & 1 \\
\hline Homemaker & 0.077 & 0.266 & 0 & 1 \\
\hline Student & 0.018 & 0.133 & 0 & 1 \\
\hline Retired & 0.253 & 0.435 & 0 & 1 \\
\hline Can't work & 0.067 & 0.250 & 0 & 1 \\
\hline Two adults in household & 0.544 & 0.498 & 0 & 1 \\
\hline Three or more adults in household & 0.092 & 0.290 & 0 & 1 \\
\hline Ratio of kids to adults in household & 0.328 & 0.633 & 0 & 16 \\
\hline
\end{tabular}
$\mathrm{N}=1,942,490$ 
Table 2: Effects of Urbanization Variables on Life-Satisfaction

(1) (2)

(3)

(4)

\begin{tabular}{lcccc}
\hline A. Density Measure & & & & \\
\hline Population density & $-0.0037 * * *$ & $-0.0022^{* * *}$ & $-0.0021^{* * *}$ & $-0.0017 * * *$ \\
& $(0.0014)$ & $(0.0007)$ & $(0.0006)$ & $(0.0005)$ \\
Individual Controls & No & Yes & Yes & Yes \\
County Unemployment Rate & No & No & Yes & Yes \\
Natural Amenities & No & No & Yes & Yes \\
Rural-Urban Dummies & No & No & No & Yes \\
& & & & \\
B. Metro Status and Size Measures & & & & \\
Micropolitan area county & $0.0158 * * *$ & -0.0009 & $-0.0047 *$ & $-0.0047 *$ \\
& $(0.0046)$ & $(0.0029)$ & $(0.0028)$ & $(0.0027)$ \\
Small metropolitan area county & $0.0236 * * *$ & -0.0007 & -0.0047 & -0.0047 \\
& $(0.0047)$ & $(0.0031)$ & $(0.0031)$ & $(0.0030)$ \\
Medium metropolitan area county & $0.0159 * * *$ & $-0.0080^{* *}$ & $-0.0140 * * *$ & $-0.0135^{* * *}$ \\
& $(0.0056)$ & $(0.0033)$ & $(0.0030)$ & $(0.0030)$ \\
Large metropolitan area county & 0.0075 & $-0.0146 * * *$ & $-0.0220 * * *$ & $-0.0206 * * *$ \\
& $(0.0075)$ & $(0.0035)$ & $(0.0033)$ & $(0.0033)$ \\
Very large metropolitan area county & 0.0006 & $-0.0210^{* * *}$ & $-0.0257 * * *$ & $-0.0186 * * *$ \\
Individual Controls & $(0.0088)$ & $(0.0047)$ & $(0.0046)$ & $(0.0044)$ \\
County Unemployment Rate & No & Yes & Yes & Yes \\
Natural Amenities & No & No & Yes & Yes \\
Population Density & No & No & Yes & Yes \\
\hline Notes: The & No & No & No & Yes \\
\hline
\end{tabular}

Notes: The sample is restricted to persons ages 18-85 living in a county that is identifiable in the BRFSS. All regressions include month and year dummies. The omitted metro category in Panel B is "non-urban" counties that are part of neither a metropolitan nor micropolitan area. Standard errors are clustered by county.

*Statistically significant at $10 \%$ level; **Significant at $5 \%$ level; ***Significant at $1 \%$ level. 
Table 3: Effects of Natural Amenities on Life-Satisfaction

\begin{tabular}{lccc}
\hline & $(1)$ & $(2)$ & $(3)$ \\
\hline January mean temperature & $0.0005^{* *}$ & $0.0011^{* * *}$ & $0.0013^{* * *}$ \\
January mean sunlight & $(0.0002)$ & $(0.0001)$ & $(0.0001)$ \\
& $0.0002^{* * *}$ & $0.0001^{* * *}$ & $0.0001^{* * *}$ \\
July mean temperature & $(0.0001)$ & $(0.00003)$ & $(0.00003)$ \\
& $-0.0018^{* * *}$ & -0.0005 & $-0.0006^{*}$ \\
July mean relative humidity & $(0.0005)$ & $(0.0004)$ & $(0.0003)$ \\
& $-0.0005^{* * *}$ & $-7.6 \mathrm{E}-06$ & $2.6 \mathrm{E}-05$ \\
Topography & $(0.0001)$ & $(0.0001)$ & $(0.0001)$ \\
& -0.0002 & $-4.7 \mathrm{E}-05$ & -0.0002 \\
Percent water area & $(0.0004)$ & $(0.0002)$ & $(0.0002)$ \\
& -0.0001 & $-2.9 \mathrm{E}-05$ & 0.0001 \\
Pacific Coast & $(0.0003)$ & $(0.0001)$ & $(0.0001)$ \\
& -0.0176 & $-0.0234 * *$ & $-0.0237 * * *$ \\
Atlantic Coast & $(0.0161)$ & $(0.0094)$ & $(0.0076)$ \\
& 0.0071 & -0.0020 & -0.0025 \\
Gulf Coast & $(0.0129)$ & $(0.0056)$ & $(0.0045)$ \\
& $0.0179 *$ & 0.0021 & -0.0074 \\
Individual Controls & $(0.0095)$ & $(0.0055)$ & $(0.0049)$ \\
Urbanization and Unemployment Rate & No & Yes & Yes \\
\hline
\end{tabular}

Notes: The sample is restricted to persons ages 18-85 living in a county that is identifiable in the BRFSS. All regressions include month and year dummies. Standard errors are clustered by county.

*Statistically significant at $10 \%$ level; **Significant at $5 \%$ level; ***Significant at $1 \%$ level. 
Table 4: Additional Results for Alternative Specifications

\begin{tabular}{|c|c|c|c|c|}
\hline & $\begin{array}{c}\text { (1) } \\
\text { Base } \\
\text { Specification }\end{array}$ & $\begin{array}{l}\text { (2) } \\
\text { Controlling } \\
\text { for Income }\end{array}$ & $\begin{array}{c}(3) \\
\text { Only Years } \\
2005-2006 \\
\end{array}$ & $\begin{array}{c}\text { (4) } \\
\text { Separating } \\
\text { Pacific Coast }\end{array}$ \\
\hline County population density & $\begin{array}{c}-0.0017 * * * \\
(0.0005)\end{array}$ & $\begin{array}{c}-0.0018 * * * \\
(0.0004)\end{array}$ & $\begin{array}{c}-0.0011^{* *} \\
(0.0005)\end{array}$ & $\begin{array}{c}-0.0017 * * * \\
(0.0005)\end{array}$ \\
\hline Micropolitan area county & $\begin{array}{l}-0.0047 * \\
(0.0027)\end{array}$ & $\begin{array}{c}-0.0116 * * * \\
(0.0026)\end{array}$ & $\begin{array}{l}-0.0003 \\
(0.0045)\end{array}$ & $\begin{array}{l}-0.0047 * \\
(0.0027)\end{array}$ \\
\hline Small metropolitan area county & $\begin{array}{l}-0.0047 \\
(0.0030)\end{array}$ & $\begin{array}{c}-0.0190 * * * \\
(0.0030)\end{array}$ & $\begin{array}{l}-0.0037 \\
(0.0049)\end{array}$ & $\begin{array}{l}-0.0038 \\
(0.0030)\end{array}$ \\
\hline Medium metropolitan area county & $\begin{array}{c}-0.0135 * * * \\
(0.0030)\end{array}$ & $\begin{array}{c}-0.0344 * * * \\
(0.0031)\end{array}$ & $\begin{array}{c}-0.0141 * * * \\
(0.0049)\end{array}$ & $\begin{array}{c}-0.0130 * * * \\
(0.0029)\end{array}$ \\
\hline Large metropolitan area county & $\begin{array}{c}-0.0206 * * * \\
(0.0033)\end{array}$ & $\begin{array}{c}-0.0489 * * * \\
(0.0032)\end{array}$ & $\begin{array}{c}-0.0204 * * * \\
(0.0054)\end{array}$ & $\begin{array}{c}-0.0199 * * * \\
(0.0033)\end{array}$ \\
\hline Very large metropolitan area county & $\begin{array}{c}-0.0186^{* * * *} \\
(0.0044)\end{array}$ & $\begin{array}{c}-0.0604 * * * \\
(0.0040)\end{array}$ & $\begin{array}{c}-0.0221 * * * \\
(0.0067)\end{array}$ & $\begin{array}{c}-0.0172 * * * \\
(0.0045)\end{array}$ \\
\hline January mean temperature & $\begin{array}{c}0.0013^{* * * *} \\
(0.0001)\end{array}$ & $\begin{array}{c}0.0011 * * * \\
(0.0002)\end{array}$ & $\begin{array}{c}0.0011 * * * \\
(0.0002)\end{array}$ & $\begin{array}{c}0.0013 * * * \\
(0.0001)\end{array}$ \\
\hline January mean sunlight & $\begin{array}{c}0.0001 * * * \\
(0.00003)\end{array}$ & $\begin{array}{c}0.00003 \\
(0.00003)\end{array}$ & $\begin{array}{c}0.0001 * * * \\
(0.00004)\end{array}$ & $\begin{array}{l}0.0001 * * * \\
(0.00004)\end{array}$ \\
\hline July mean temperature & $\begin{array}{l}-0.0006^{*} \\
(0.0003)\end{array}$ & $\begin{array}{l}-0.00002 \\
(0.0004)\end{array}$ & $\begin{array}{l}-0.0004 \\
(0.0004)\end{array}$ & $\begin{array}{c}-0.0006^{* *} \\
(0.0003)\end{array}$ \\
\hline July mean relative humidity & $\begin{array}{l}0.00003 \\
(0.0001)\end{array}$ & $\begin{array}{l}0.00002 \\
(0.0001)\end{array}$ & $\begin{array}{l}0.00008 \\
(0.0001)\end{array}$ & $\begin{array}{l}0.00002 \\
(0.0001)\end{array}$ \\
\hline Topography & $\begin{array}{l}-0.0002 \\
(0.0002)\end{array}$ & $\begin{array}{l}-0.0001 \\
(0.0002)\end{array}$ & $\begin{array}{l}-0.0003 \\
(0.0003)\end{array}$ & $\begin{array}{l}-0.0002 \\
(0.0002)\end{array}$ \\
\hline Percent water area & $\begin{array}{c}0.0001 \\
(0.0001)\end{array}$ & $\begin{array}{l}0.00004 \\
(0.0001)\end{array}$ & $\begin{array}{c}0.0001 \\
(0.0001)\end{array}$ & $\begin{array}{c}0.0001 \\
(0.0001)\end{array}$ \\
\hline Pacific Coast & $\begin{array}{c}-0.0237 * * * \\
(0.0076)\end{array}$ & $\begin{array}{c}-0.0158 * * \\
(0.0077)\end{array}$ & $\begin{array}{l}-0.0165 \\
(0.0104)\end{array}$ & \\
\hline Atlantic Coast & $\begin{array}{l}-0.0025 \\
(0.0045)\end{array}$ & $\begin{array}{l}-0.0027 \\
(0.0053)\end{array}$ & $\begin{array}{l}-0.0036 \\
(0.0065)\end{array}$ & $\begin{array}{l}-0.0034 \\
(0.0045)\end{array}$ \\
\hline Gulf Coast & $\begin{array}{l}-0.0074 \\
(0.0049)\end{array}$ & $\begin{array}{l}-0.0009 \\
(0.0048)\end{array}$ & $\begin{array}{l}-0.0004 \\
(0.0078)\end{array}$ & $\begin{array}{l}-0.0080 \\
(0.0050)\end{array}$ \\
\hline Pacific Coast Washington & & & & $\begin{array}{l}-0.0053 \\
(0.0122)\end{array}$ \\
\hline Pacific Coast Oregon & & & & $\begin{array}{l}-0.00004 \\
(0.0074)\end{array}$ \\
\hline Pacific Coast Northern California & & & & $\begin{array}{c}-0.0454 * * * \\
(0.0089)\end{array}$ \\
\hline Pacific Coast Southern California & & & & $\begin{array}{c}-0.0382 * * * \\
(0.0088)\end{array}$ \\
\hline Individual Controls and Unemp. Rate & Yes & Yes & Yes & Yes \\
\hline
\end{tabular}

Notes: The sample is restricted to persons ages 18-85 living in a county that is identifiable in the BRFSS. All regressions include month and year dummies. Standard errors are clustered by county. *Statistically significant at $10 \%$ level; **Significant at $5 \%$ level; ***Significant at $1 \%$ level. 